$\because$ 



\title{
THE BACTERIOLOGICAL DIAGNOSIS OF CERTAIN INFECTIOUS DISEASES IN CONNEXION WITH PUBLIC HEALTH WORK
}

\author{
BY \\ SHERIDAN DELÉPINE, M.B., B.Sc. \\ PROCTHR PROFHSSOR OF PATHOLOGX, OWENS COLTEGE, \\ VICTORIA UNIVERSITY.
}

Reprinted from THE LANCET, February 5, 12, and 19, 1898. 



\section{THE BACTERIOLOGICAL DIAGNOSIS OF CERTAIN INFECTIOUS DISEASES IN CONNEXION WITH PUBLIC HEALTH WORK. ${ }^{1}$}

\section{INTRODUOTION.}

(A) A QUARTER of a centary has not elapsed since the time when we generally considered disease to be essentially a disorder of function or structure. The belief in the action of external causes did undoubtedly exist in the mind of our predecessors, but few would have been prepared to admit, as proved, thirty years ago, that such prevalent diseases as tuberculosis and malaria were due to the penetration into, and evolution in, our bodies of living organisms which, by their invasion, multiplication and development, were mainly responsible for the course which these diseases take. The transient action of physical or chemical factors and the existence of a number of diathetic tendencies were chiefly blamed, and the course of disease, according to the then current notions, was determined by the lesions resulting from the disordered activities of the tissues composing the body. A chill, retained bile, sudden stoppage of perspira. tion, exposure to damp, to heat, to cold, \&c., were thought enough to disturb the nervous or circulatory mechanism of one or other organ; as a result of this we had diseases of the liver, kidney, heart, \&c. The lesions found in these organs were made responsible for most of the symptoms observed. These lesions in the mind of most constituted the disease.

There were miasmatic or contagious diseases in which the existence of a contagium was admitted, often on a theoretical basis, but the diagnosis of these diseases was based entirely on the study of symptoms and lesions. The only information which was sought was that which could be found by anatomical or physiological methods during life or after death. The medical man was occasionally helpsd

1 A paper read at the Conference of Medical Officers of Health at the Sixteenth Congress of the Sanitary Institute, Leeds, on Sept. 15th, 1897. 
by events when a doubtful case, say of diphtheria, would prove its nature by infecting other persons. That this spontaneous experimental method was not always taken advantage of is well proved by the fact that the contagious nature of such a prevalent disease as tuberculosis was overlooked by the great bulk of the medical profession for many centuries.

There is not one of us who has not experienced either in his own practice or in that of his colleagues and even of his teachers how of ten symptoms and even lesious are deceptive. We are constantly reminded by the results of necropsies, by unexpected deaths or recoveries, how uncertain the diagnosis of atypical cases of disease is. When we find general tuberculosis or chronic septic diseases mistaken for typhoid fever, cases of scarlet fever or septic tonsillitis taken for diphtheria-and that not always by inexperienced men but even by high authorities-we cannot help feeling that any method which could in any degree make diagnosis more certain would be a great boon to human kind. This desire, which is common to all thoughtful medical men, is perhaps felt more keenly by medical officers of health.

$\mathrm{By}$ a discovery of certain pathogenic germs it is possible to foretell more accurately the ultimate issue of the reaction which they produce than it is to surmise what will occur by the observation of the phenomena arising at any of the intermediate stages of the reaction; this is a clear and well-admitted result of the work of Pasteur and of his successors. A membranous sore-throat, a pleuritic effusion, may leave us in doubt as to the probable nature of a case; but the discovery of the bacillus of tuberculosis, of diphtheria, of typhoid fever, \&c., will at once remove any doubt from our mind and indicate at the same time the most suitable method of dealing with the case?

(B) I have reminded you in a very general and superficial way of these few elementary facts to make clear to you the spirit in which I approach the subject on which I have been asked to address you. The ordinary methods of clinical diagnosis are still relied upon in most districts. Statistical retarns, preventive measures, are still based on them. Yet in the case of some of the most prevalent diseases microbiology has given us the means of obtaining results which, if not perfect in every respect, are much more accurate and speedy than the ordinary clinical methods. If I am correct in making this statement-and I hope I shall prove this to be the case-it is highly desirable that advantage should be taken of these new methods by all medical rnen and more especially by those who have charge of health offices.

It is of the highest importance that errors of diagnosis should be reduced to the utmost. Errors of diagnosis vitiate and render partly useless much of our work, and that for a number of reasons. 1. Statistical returns indicate to us the 
prevalence of certain diseases at various times and in various places and also the amount of improvement which preventive measures have produced, but these retarns will be misleading if not based on sufficiently accurate data, comparable with each other wherever and by whomsoever they have been collected. 2. Isolation of patients affected with a certain contagious disease in hospitals provided for that disease becomes a source of contagion if patients affected with other diseases are sent by mistake to those hospitals. 3. The cost of isolation is thereby increased as well as the waste of working energy. 4. The knowledge of disease and of its treatment is retarded owing to the fact that practices based on error, not being checked, are allowed to grow into routine, supposed cases of recovery from certain diseases are recorded where the disease never existed, fatal terminations follow supposed mild illnesses which should have taken a benign course, and doubt is made to reign where progress might have been expected. It must be well understood that I speak of those errors of diagnosis to which the most careful and experienced men are liable. As to those errors which are the result of gross ignorance or of systematic practice I do not even allude to them here as their existence should be ignored, but so far as they are a discredit to our profession any method which should give the means of checking such abuses would be of great value.

I think that so far I have expressed nothing which will not be readily admitted. There remains for me to prove by practical results that we have now at our disposal several bacteriological methods giving us the means of increasing considerably the accuracy of early diagnosis of a certain number of infectious diseases. As these methods have been extensively tried in my laboratory at the Owens College for the last five years I am able to submit to you the results of $\mathbf{m y}$ personal experience.

The diseases with regard to which I have been able to give assistance to the Public Health Department of Manchester and surrounding towns have been chiefly tuberculosis, typhoid fever, diphtheria, cholera, epidemic diarrhœa or gastro-enteritis, hydrophobia, anthrax and food poisoning. This naturally does not include all the cases in which assistance may be given by bacteriology. To show how the work is done and answers administrative purposes it will be sufficient to refer specially to three diseases which are constantly with as, and the bacteriological diagnosis of which is based on four different types of methods. I refer to tuberculosis, diphtheria, and typhoid fever. 


\section{TUberculosis, WITH SOME Remarks oN Summer}

\section{DiARRHCEA.}

With regard to tuberculosis, this not being yet a notifiable disease, there is no question of case diagnosis ${ }^{2}$; our work has been chiefly directed to the detection of tuberculous milk. During the twelve months ending with last August 103 specimens of milk have been sent to me for examination.

Of these twenty-four had been collected for Dr. Niven in Manchester byres from cows affected with tuberculosis, most of which had also disease of the udder. These specimens were collected by Mr. King, the chief veterinary inspector, and his assistants, and sent immediately to the laboratory. I need hardly say how important a part of a systematic inspection of cowsheds the examination of milk is. This was abundantly proved by the results obtained.

The milk being drawn direct from the udder of an infected cow into a sterilised vessel is that of a single animal and is unmixed with milk of other cows. On arrival at the laboratory the sample is at once examined in the following way. $80 \mathrm{c.c}$. of the milk are centrifugalised in two stout cylindrical testtubes holding $40 \mathrm{c.c}$. each. For this purpose I use a centrifugal machine giving 3000 revolutions to the minute and I allow the machine to work for fifteen minutes. The tubes have been previously sterilised by steam. They are kept closed with an indiarubber cap till the moment they are used. When this part of the process is completed the thickness of the layer of cream and the diameter of the sediment are measured, the colour of the milk and sediment are noted, and the reaction and specific gravity of the milk left in the bottle are taken. These preliminary tests are useful chiefly to give a general idea of the state of the specimens as they reach the laboratory and seldom yield information of any importance except for purposes of control. Microscopical preparations are then made with the cream and sediment of the centrifugalised milk. One drop of the cream is taken with a sterilised platinum loop and spread on a cover-glass and allowed to dry; the cream together with the milk is then removed by means of a wide pipette connected with a vacuum apparatus, this is done with the tube standing vertically and without disturbing the sediment. When only a thin layer of milk remains the tube is inclined gently so as to expose the

\footnotetext{
2 We hope however to be able, before long, to extend our work in that
} direction. 
sediment which adheres firmly to the bottom of the tube and a small drop of it is taken and spread on a cover.glass; this is done with a platinum loop holding from 2 to 3 milligrammes. Several cover-glasses are prepared in this way. Some drops of cream and sediment can then be examined at once for the detection of cells, foreign bodies, and motile bacteria. The other drops spread in thin layers are allowed to dry, passed three times through the flame of a Bunsen burner and then left for several hours (usually twenty-four) in a mixture of equal parts of ether and absolute alcobol. At the end of that time the alcohol and ether are heated over a water bath to complete the extraction of the fat, the cover-glasses are taken out, washed with absolute alcohol, and are then ready for staining by one of the usual methods. If they are stained for tubercle bacilli the "Ziehl Neelsen" method is most suitable. But if one desires to stain the preparations with ordinary solutions of aniline dyes for special purposes the film should be submitted first to the action of some dilute acid for a few seconds. I find that sulphuric acid 10 per cent. answers very well for this purpose. If acid be not used the proteid matter coagulated on the cover-glass in the spaces between the fat globules stains deeply and neither micro-organisms nor cells can be seen distinctly. This allows one, however, to obtain a permanent preparation showing clearly the number and size of the fat globules. Immediately after preparing the films two guineapigs are inoculated, each with the sediment of $40 \mathrm{c.c}$. of milk. The sediment contained in each tube is mixed with a little of the supernatant milk, so as to make a total quantity of 2 c.c. for subcutaneous injections and 5 c.c. for peritoneal inoculations.

The results obtained by these methods have already been recorded in Dr. Niven's " Report on the Manchester Cowsheds" issued at the beginning of 1897 . In Professor Hope's "Report of the (Liverpool) Medical Officer of Health on Taberculosis as affecting the Milk-Supply of the City" (May 6th, 1897) the results of another investigation, having for its object the detection of tubercle bacilli in milk supplied to cities, are given. Both in Manchester and in Liverpool a large number of specimens supplied from the country to town milk-sellers have been collected by inspectors at railway stations or elsewhere as the milk reached town. I have examined all the specimens collected in Manchester and part of the specimens collected in Liverpool-in all eighty samples. The method followed by me was exactly the same as the one already described.

Regarding the value of the methods I have described I may say at once that the microscopical method is of very little use for the detection of tuberculous milk. It is only when tubercle bacilli are very abundant that they can be discovered without a considerable loss of time. Even after separating the sediment in which a large portion of the bacilli are found it is necessary to examine 
several preparations before one or two bacilli can be discovered. The amount of sediment obtained from 80 c.c. of milk seldom exceeds, it is true, 200 milligrammes, but supposing there were 300 bacilli in the 80 c.c. of milk examined and that 200 had been carried down into the sediment (many are carried up with the cream) the search might be very lengthy. If the bacilli were very equally distributed in the sediment each milligramme of the sediment would contain one bacillus, and as each film is prepared with two or three milligrammes of sediment not more than two bacilli should be expected on each preparation. But many of the bacilli are found in small groups of three, five, ten, or more. It is not likely, therefore, that there would be more than forty of these groups in the sediment, and it might be necessary to examine as many as five drops before bacilli were detected even in the case of a milk containing the large number of bacilli I have supposed. On this supposition there should be nearly 10,000 bacilli in a pint of milk, and yet it might take several hours to detect them unless, as sometimes is the case, some were found in the first drop examined. This shows that when tubercle bacilli are easily found in a sample of milk by the microscopical method, the bacilli are usually very abundant, but when the tubercle bacillus is not found, even after a search extending over several hours, it is not safe to assume that the milk was not tuberculous and incapable of doing harm. On the other hand it is well known that when a guinea-pig is inoculated with even a few bacilli it invariably becomes tuberculous. Were they ten times less numerous than I have supposed in the example I have just given, the number of tubercle bacilli found in the sediment of 40 c.c. of milk would be still easily detected, since material containing eight or ten tubercle bacilli, revealable by ordinary staining reactions, would be enough to produce tuberculosis in the guinea-pig. There can be therefore no doubt as to the superiority of the inoculation method when exact results are wanted. This is well shown by the outcome of the investigations to which I have already referred. Taking only two of the series of samples I have examined: Of twenty-four specimens of unmixed milk obtained from tuberculous cows, two were found by microscopical examination to contain tubercle bacilli clearly demonstrable; six were found to be tuberculous by the inoculation method, including the two in which bacilli had been detected microscoplcally. Of forty-five specimens of mixed milk (in which the milk of tuberculous cows was diluted with milk of non-tuberculous cows) it was not possible in any case to discover the tubercle bacilli by a careful examination of two drops of sediment. Three of these specimens were proved to be tuberculous by the inoculation method.

The microscopical examination, however, is not without use, for in all the cases which were proved to be tuberculous by inoculation the milk was found to contain a large number 
of leucocytes and epithelial cells; this presence of cells was also recognised in milk coming from udders affected with non-tuberculous mammitis and therefore is not diagnostic of tuberculosis, but tuberculosis was never communicated in my experiments by milk poor in cells. This is a confirmation of the well-known fact that the milk of tuberculous cows does not as a rule become infectious when the udder is not tuberculous.

The testing of milk by inoculation is not only useful with regard to tuberculosis, for in a large proportion of cases milk which has been badly kept exhibits virulent properties in various degrees. Thus, after excluding the tuberculous samples, I can classify the samples I have examined as follows :-

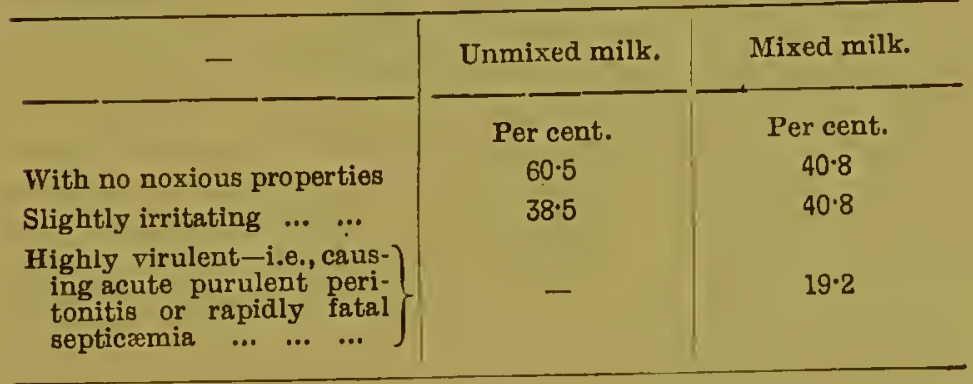

It will be at once evident that the proportion of mixed milk which are capable of producing mischief are much greater than that of unmixed milk. I cannot here enter into details which have been recently published in the Journal of Comparative Pathology and Therapentios (December, 1897), but I may state that this difference is chiefly due to the multiplication of micro-organisms which are introduced into the milk at the time of milking or afterwards when the milk is unduly exposed to various contaminations; when the temperature is favourable the microbes multiply very rapidly. This occurs chiefly in summer and I have found good reasons to believe that it is a very important cause of summer diarrhca.

It is well to remomber that the bacillus which is most to blame, increases rapidly in number when milk is kept, and especially when kept at summer temperature, causes great mortality in the guinea-pigs inoculated peritoneally. It is therefore most important in conducting any investigation on tuberculosis to inoculate as soon as possible after milking in order to prevent the mortality and lesions due to that microbe. ${ }^{3}$ There remains only to add that to ensure thoroughness in investigations of this kind it is desirable that certain data should be supplied with each sample of milk. The

3 Or else the milk must be kept in ice from the time of collection to that of examination. 
following schedule which I have adopted for anmixed milk collected in the stable bas been of great use to me.

This Label is to be fixed to each Sample of Milk sent to the Bacteriological Laboratory for Analysis, and all the information obtainable entered under the following heads.

Name of Farm

Lab. M. No.

\section{Situation}

Description of Cow

No. of Cows kept in same Byre

Byre:-Clean, Not clean; Ventilated: Well, Badly Lighted: Well, Badly.

Hands of Milker :-Clean, Not clean. Teats :-Clean, Not clean.

Does the Cuw show any evidence of Disease?

Has the Cow been submitted to tuberculin test?

Where? \{

Reaction:

Nature of Food.

Quantity of Milk yielded

Date of Milking

'Bottling Sample

Bottle sterilised or not

hour A.-P.M. Signature of

Yes or No.

N.B.-Bottle, which should hold 8 oz., can be sterilised by boiling half-hour in water after cleaning. Stopper should be of indiarubber and also sterilised.

With regard to unmixed milk it is desirable to know (1) the farm from which the milk comes; (2) the time of milking; (3) the time of collecting the specimen; (4) the temperature of the milk at the time of collection, and also the external temperature ; and (5) that the bottle in which the specimen was collected had been sterilised. Other questions are of interest from an administrative point of view, but for investigation purposes the above are the most useful in helping to interpret the results obtained.

\section{DIPHTHERIA.}

So much is already known of the methods in use for the bacteriological diagnosis of diphtheria that I shall simply describe the way in which the work is carried out in my laboratory, and though we cannot claim in Manchester to have been the first to apply this method of diagnosis in public health work we have by careful consideration of the difficulties to be overcome obtained an encouraging measure of success.

The bacteriological diagnosis of diphtheria is based on the fact that the bacillus discovered by Löfter, the bacillus of diphtheria, is present in inflammatory products covering mucous membranes and in inflamed membranes affected with diphtheria. This bacillus is not alone present but is usually accompanied by other organisms, mostly staphylococci and streptococci. If the surface of a solid medium specially 
suitable for the growth of the diphtheria bacillus, such as ox or horse serum, or better still the mixture of alkaline glucose, bouillon and serum introduced by löfller, be inoculated with a very thin layer of the inflammatory products and incubated at a temperature of from $35^{\circ}$ to $37^{\circ} \mathrm{C}$. the bacillus of diphtheria will generally grow more rapidly than, or at any rate as rapidly as, any of the other micro-organisms present, so that if from twelve to twenty hours after inoculation the surface of the inoculated serum be examined it is found to be covered with colonies of various kinds, among which those of the diphtheria bacillus will be present. As some other organism may simulate in mode of growth the diphtheria bacillus all the suspicious colonies are examined microscopically in the usual way-i.e., thin films are prepared, stained with diluted carbol fuchsin, and examined with a $\frac{1}{12}$ th oil immersion objective. The bacillus is easily recognised from other organisms by its size, its mode of grouping, its unequal staining, and the tendency which the extremities of some have to swell, giving to the rod a clubshaped appearance. There are a thick, short variety and a long variety of the organism and there are intermediate shapes between the two. If tested by inoculation some of the bacilli, after pure cultivations have been obtained, show great virulence; they are mostly those of the long type, others, generally short, show little virulence. I have found it impracticable to test all the bacilli by inoculation and $I$ have made it a rule to report diphtheria bacilli as present whether the long or the short form was found whenever they were quite typical. Occasionally it is difficult to be absolutely certain about the exact nature of certain short bacilli and in all such cases a doubtful report is issued. The routine followed will best be explained by reading the forms which Dr. Niven issued after we had considered the matter together when the work was started officially in Manchester.

The first circular was to explain to the medical men of the district what had been arranged. This circular will show clearly that the aim in placing bacteriological examination at the disposal of medical men was not to check the diagnosis of cases absolutely clear, but to give facilities for the early or late diagnosis of any case with regard to which the possibility of diphtheria was suspected. From an administrative point of view it is, however, most desirable that all cases should be examined bacteriologically.

$$
\text { Public Health Office, Town Hall, Manchester, }
$$
Feb. 3rd, 1896.

Deld on Jan. 29th the Sanitary Committee of this city confirmed a resolution passed by the hospitals sub. committee that facilities be afforded to medical men in the diagnosis of committee that many cases of diphtheria, especially those of a small degree of severity, are cases of diphtheria, especially those of ame if unrecognised they are difficult to recognise. At the same time if um if such slight are liable to spread the disease. On the other hand. if such slight cases are reported it is not easy to get the patients to believe that they 
have suffered from so formidable a disease as diphtheria or to induce them to have the requisite measures of isolation and disinfection carried out. In the same way grave difficulties arise as regards the removal of such cases to hospital.

In order to obviate these difficulties and to assist both the practitioner and the Health Office the Sanitary Committee have arranged with the council of Owens College and Professor Delépine to receive from him a diagnosis of the nature of material obtained from cases

A number of tubes are kept at the Health Office in the town-hall, each containing materials by means of which a practitioner can obtain from a suspected case matter for transmission to the pathological laboratory at Owens College. These tubes are enclosed in a wooden case on the outside of which are printed instructions for taking

Medical men are requested to be careful to fill in the particulars asked for as no bacteriological examination will be made in the absence of sufficient information.

Should the bacteriological examination show that the case is not one of diphtheria the fee of $2 s$. $6 d$. for notification will be paid just as if no bacteriological examination had been made.

On the other hand, if no bacteriological examination is requested, this will be regarded as a proof that the case reported admits of no doubt. Applications for tubes must be made to the Health Office. The tubes may afterwards be forwarded direct to the College. The diagnosis, again, can only be obtained from the Health Office.

It is, however, the aim of the Sanitary Committee to shorten as much as possible the period between the first report of the case and the receipt by the medical attendant of the bacteriological diagnosis.

If the medical attendant will telephone to the Health Office from the nearest police-station a request for a tube this will be at once sent by messenger to his residence or to the address of the patient, as the medical attendant may desire. If he is prepared at once to take a specimen for diagnosis the messenger will wait to receive the tube from him charged with the matter to be examined and will convey it forthwith to the College. The diagnosis will be given to the medical attendant only on the following day. It will be necessary, however, that the tube reach the laboratory by 3 mit on necessary, the days, Monday to Friday, and on Saturday by 1 P.M., otherwise the diagnosis will be delayed by one day. No diagnosis will be given on Sunday.

The expense of the bacteriological examination will be defrayed by the Corporation and it is hoped that full advantage will be taken of the opportunities thus afforded.

In order that medical men may familiarise themselves beforehand with the procedure which they will require to adopt a copy of the instructions printed on the outside of the wooden case is enclosed.

James NIVBN, Medical Officer of Health.

The tubes which I have devised for collecting samples present certain advantages which render work easier and the following description explains the way in which the apparatus is constructed and the manner in which it is used. In Fig. 1 is shown a section through the wooden case (A); this case is square externally, and on the outside of it is pasted the label on which all the particulars are entered. It

4 The wording of the circular has been slightly altered in a few places. The time limits given in these forms were rendered necessary by the conditions under which a large amount of work had to be done at first as I could only give a limited part of my time to it. With my present staff of assistants such limits are now less necessary. I am not sure, however, that there is very great advantage in receiving tubes at all times of the day unless some arrangement be made to do part of the examinations at night. An interval of at least twelve to serenteen hours must be allowed between inoculation of the tubes and the examination of the colonies. 
FIG. 1.

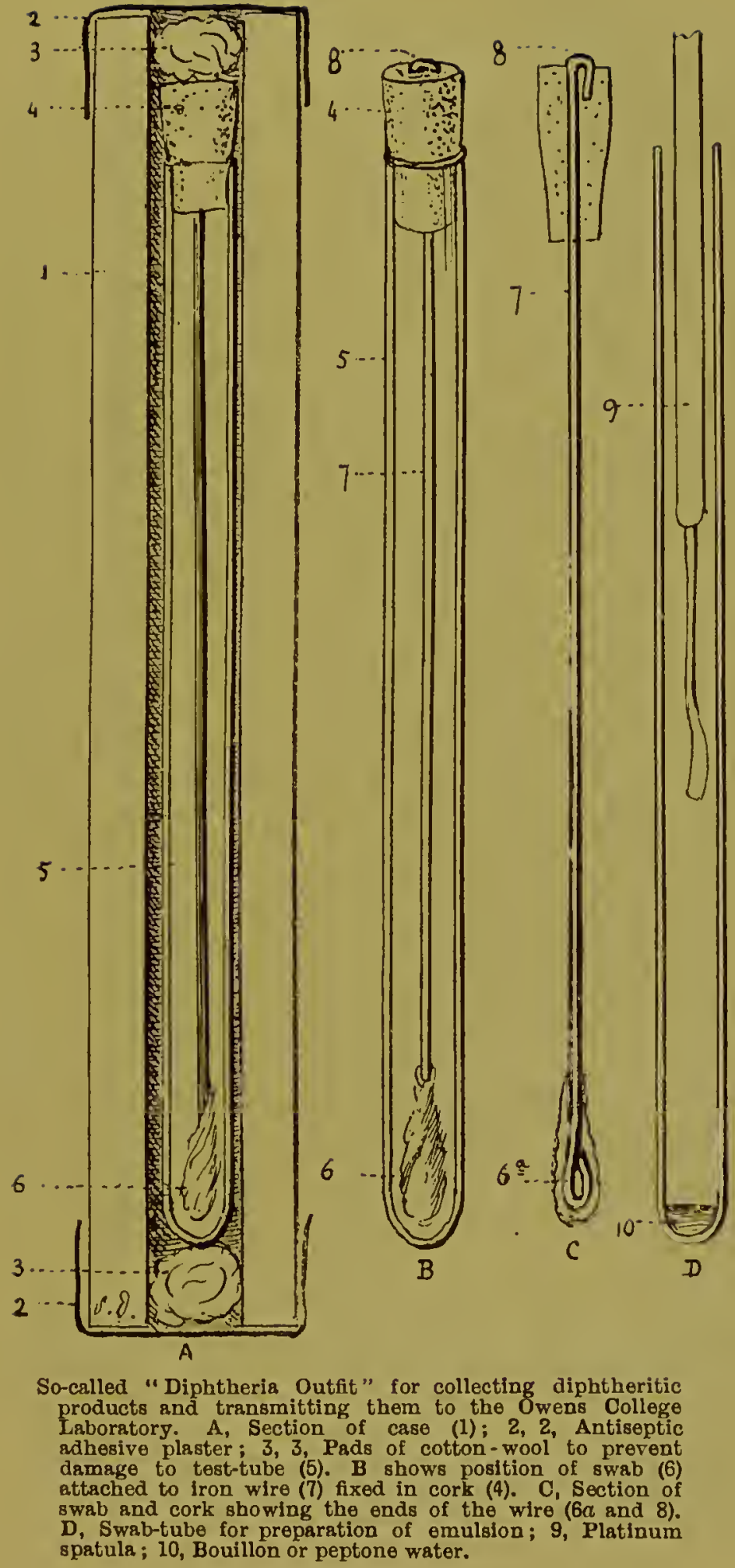


has a cylindrical perforation, extending from end to end, into which the swab tube (5) is placed for transmission by post to and from the laboratory or sanitary office. The wood of this case is prepared by soaking in a 5 per cent. alcoholic solution of perchloride of mercury. The two ends of the case (1) are closed with antiseptic adhesive plaster (2), and the ends of the glass tube (5) are protected by two pads of cotton wadding (3). The swab tube (B) is a narrow test-tube (5), closed by a long cork (4) through which is passed a firm galvanised iron wire very nearly as long as the glass tube. Round the free extremity of this wire absorbent cotton-wool is twisted so as to form a soft swab which should not be too bulky. These tubes are thoroughly sterilised in the autoclave, the cork lying loosely in their mouth. After sterilisation they are removed from the autoclave, dried in the hot-air oven, and whilst quite hot the cork is firmly pushed in so as to completely close the tube. The swab tube is then introduced into a sterilised case. The swab-holder (C) shows how the wire is fixed in the cork and how the swab end $(6 a)$ is bent so as to prevent the possibility of the wire hurting the mucous membrane on which it has to be rubbed firmly. The cork is used to hold the swab; the length of the wire is such that products can be collected from the pharyox and false vocal cords without the operator's fingers touching the lips of the patient. The swab tube (D) is used to prepare the emulsion with which the Löfller's serum is inoculated. A small quantity of alkaline bouillon or peptone water (10) is introduced into the tube, the swab is well rubbed in it until the fluid is quite turbid, then the platinum spatula (9) is dipped into the fluid and rubbed successively on the slanting surface of the solidified sernm contained in three different tubes.

The clinical details asked are not used as guides at all in the bacteriological work, they are wanted only for use afterwards to find out any relations which might exist between certain types of cases and the bacteriological results obtained. The details obtained in this way are communicated to the medical officer of health as they might prove of ase to him in tracing certain epidemic types. Dr. Niven on his side gives me all the information which he can obtain regarding the course followed by the illness on which reports have been sent from the laboratory. In this way documents are accumulated which make it possible to test the value of our work and to carry out certain investigations.

The total number of cases of suspected diphtheria reported upon from the end of August, 1896, to the end of August, 1897, has been 394, of which 311 were Manchester cases and 83 from Stockport, Salford, Kiccles, Withington, Moss Side, Stretford, and Crewe. ${ }^{5}$ In 119 cases diphtheria bacilli were

5 Since this report was written it has become possible to obtain the number of cases examined from Jan. lst to Dec. 31 st, 1897; 500 cases were reported uoon during that period. 


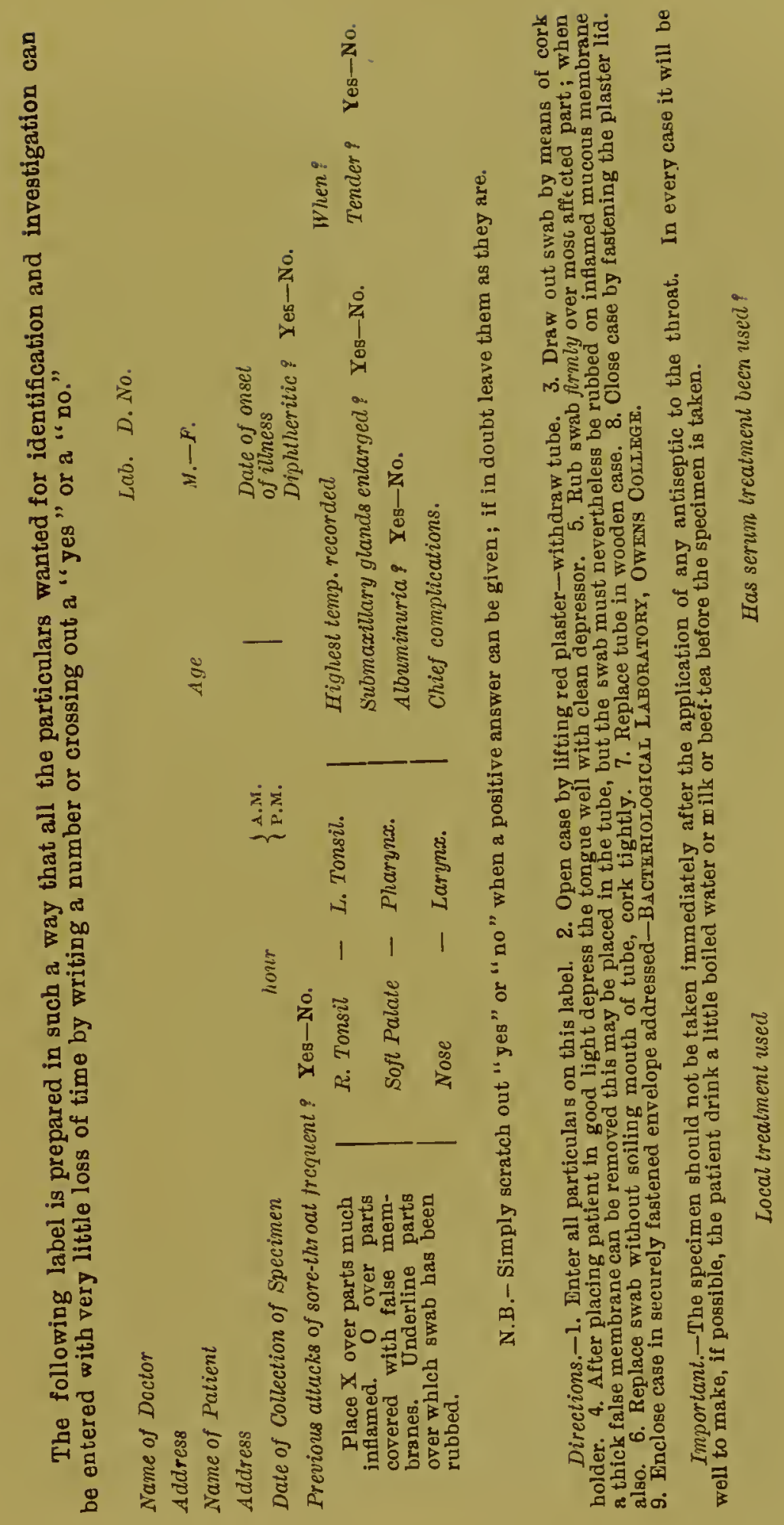


detected. In 271 no diphtheria bacilli were found. In 4 cases doubtful results were obtained and were reported as such. So that in 390 cases out of 394-i.e., in very nearly 99 per cent. of the cases-deflnite results, either positive or negative, were obtained.

Regarding the amount of agreement observed between the laboratory results and the further clinical study of the cases I have been able through Dr. Niven's kindness to obtain the following information concerning the Manchester cases. 311 specimens taken from Manchester patients were examined; in 89 of these diphtheria bacilli were found and as the bacteriological diagnosis was invariably accepted nothing need be said about these cases. In 218 no diphtheria bacilli were found. Our negative report was not accepted by the medical attendant in 20 cases. In about half of the remaining cases the medical men wrote in answer to inquiries that they accepted our diagnosis. Regarding tbe other half we could get no information, but we had good reason to believe that if fault had been found with our report this would have been freely expressed, for the medical men were earnestly asked to do so without restraint.

Excluding the four doubtful ones there remain 307 cases. Our bacteriological reports were openly accepted in some 188 cases, received without opposition in 99 cases, and challenged in 20 cases. Of these 20,3 which were admitted in the fever hospital developed scarlet fever; another was seen by Dr. Niven, who satisfied himself that the patient was not suffering from diphtheria; another case had, judging from the history afterwards obtained, scarlet fever and in another case the patient recovered so rapidly that the diagnosis of diphtheria was difficult to support on any clinical ground. Of the 14 cases remaining after these have been excluded 2 seem to have been cases of diphtheria, but in none of the others has the information given us been sufficiently clear to make it certain that from a clinical point of view there was no doubt as to the nature of the illness. If we admit, however, that in 14 cases the bacteriological method failed to give accurate information this amounts to saying that in 4 per cent. of the cases on which we reported our opinion was not supported by the course taken by the case.

If we compare this result of bacteriological examinations as tested by clinical observation with those of clinical observation as tested by the bacteriological method we find that out of 307 cases suspected of being possibly affected with diphtheria not less than 218 were, bacteriologically, not cases of that disease, or if we exclude the 14 cases just alluded to in which our opinion was openly challenged, without our being able to prove that the error was not on our side, we find that 204 out of 293 cases of suspected diphtheria were affected with some other disease. This means doubt in 69 per cent. of the cases to compare with our 4 per cent. of error. But it might be said that the cases about which we have not 
received any expression of agreement or disagreement from the medical attendant should not be included in our estimates. Such an objection is easily overcome. After excluding those cases there remain still 207 reports, regarding which we have a definite opinion from the medical men. Out of these we have, on one side, 14 cases of unmistakable disagreement and, on the other side, 89 positive cases and 104 negative cases in which our finding was clearly accepted or proved to be correct at the fever hospital. According to this estimate the clinical doubts would not be less than 50 per cent., whilst the bacteriological errors would not be more than 7 per cent.

It is not necessary for me to push these remarks further to prove my point, but I may add that at least ten of the cases in which no diphtheria bacilli could be found turned out after admission at the Monsall Hospital to be cases of scarlet fever, two of typhoid fever, and one of thrush. I give these only as examples of the difficulties of ordinary diagnosis and to show that although I have accepted as possible cases of error on my side fourteen cases (in which the clinical diagnosis of diphtheria was upheld by the medical man notwithstanding our not finding diphtheria bacilli), it is more than probable that I have under-estimated the accuracy of the bacteriological work. I should say that whenever we were at all dissatisfied with the swabs sent to the laboratory, either because they did not seem to bave been well loaded with morbid products or contained few or no cultivable bacilli (probably owing to the action of antiseptic applications), we invariably requested that another sample should be sent. I may also add that in several cases of reexamination we obtained in the second and sometimes in the third examination the same results as in the first, showing that the method was applied with sufficient care to ensure constancy of results.

There are many interesting points in connexion with the practical effects of the utilisation of bacteriological diagnosis which I must reserve for a farther communication by Dr. Niven and myself.

\section{TýhoID Fever.}

The method of diagnosis I use in the case of typhoid fever differs entirely from those I have described in connexion with tuberculosis and diphtheria. Here it is not for the bacillus we look but for a peculiar property acquired by the blood of patients affected with typhoid fever. This blood, when brought in contact with living and active cultures of the typhoid bacillus, paralyses the bacilli and causes them to run together and form clumps; the two phenomena of immobilisation and agglomeration constitute the typhoid reaction first described by Widal at the end of the month of June, 1896. Immediately on hearing of this 
discovery I tested its value on hospital cases and at the end of July, 1896, had already obtained fall confirmation of Widal's statements. I devised the method which has been in use in my laboratory ever since, and later I had the pleasure of finding that Widal himself considered it most suitable in every respect. Before using the method in general practice I tried it carefully on some fifty hospital patients during the months of September, October, and November, Dr. Marsden, the resident medical officer at the fever hospital, keeping the patients under observation, and Dr. E. Sidebotham assisting $m e$ in this second series of experiments. ${ }^{6}$ The results were so satisfactory that in January Dr. Niven determined to use this method in connexion with his work. Since then several other public health departments have applied to the college to have the same facilities granted to them. The number of cases which I can record does not therefore correspond to the work of a full year, but to about ten months in Manchester and less in the case of other towns. The arrangement adopted and methods used can be well understood by reading the following documents.

Public Health Office, Town Hall, Manchester, Jan. 8th, 1897.

Drar Srr - At a meeting held on Wednesday, Dec. 3Uth, 1896, the Sanitary Committee of this city confirmed a resolution passed by the Hospitals Sub-committee that facilities be afforded to medical men in the diagnosis of caes of typboid fever. The investigations of Widal, whose results have been confirmed by Professor Delépine, make it certa'n that by means of a small amount of blood. sucb that the loss of it can make no appreciable difference to the patient, it is essy to tell by a bacteriological reacion whether the patient is suffering from typhoid fever or not. Now by clinical examination it is often very difficult in the early stages of the disease to say whether an illness is or is not typhoid fever.

In consequence of this difficulty csses are not notified sufficiently early to tbe public bealth officer to enable tbe medical attendant and the sanitary authority to take the $\mathrm{m}$ (st effectual measures for preventing communication of the disease from the sick person to members of the same family and to others. Not only so, but many persons are sent in to hospital as soffering from ty phoid fever who are really affected with other conditions.

Then, moreover, there is no doubt that if the circumstances of the sick are such that they ought to be treated in bospital it is much better for them that they sbould be removed from home early in the course of their illness.

All these considerations make it matter for great congratulation both to the medical attendant and to tbe public tbat bacteriology should lend effectual aid in clearing up doubtful cases of this most difficult malady; and tbe Sanitary Committeo have therefore made a similar arrangement with the Council of Orens College and with Professor Delépine to that which has worked so well in tbe case of diphtberia.

A number of pipettes are kept at the Public Heall $\mathrm{b}$ Office in the townhall by means of which a small amount of blood may be obtained from a suspected case for transmission to tbe pathological laboratory at Owens College. Accompanying each pipette is a paper containing instructions for the obtaining of material and psrticulars requiring to be filled in.

Medical men are requested to be careful to fill in the psrticulars asked for as no bacteriological examination will be made in the absence of sufficient in formation.

6 See The Lancet, Dec. 5th and 12th, 1896. 
Should the bacteriological examination indicate that the case is not one of typhoid fever the fee of $2 s .6 d$. for notification will be paid just sif ty periological examination had been made.

is requested

the other hand, if no bactorted admits of no this will be regarded as a prot must be made to the Public Health doubt. Applications for pipettes must be madarded direct to Professor Office. The pipettes must afterwards be forwarded directy be obtained Delépine at Owens College.

from the Public Health Office.

It is, however, the aim of the Sanitary Committee to shorten as , much as possible the perod ant of the bacteriological diagnosis.

receipt by the medical attendant of the bacteriological diagnosis.

from the nearest police-station a request for a piptte this will be at once sent by messenger to his residence or to the address of the patient, as theimen for diagnosis the messenger will wait to receive the to take a specim him charged with the matter to be examined, and will pinvey it forthwith to the laboratory. The diagnosis will be given to the medical attendant only on the following day. It will be necessary, however, that the pipette reach the laboratory by 1 P.M. on any one of the days Monday to Friday and on Saturday by 10 A.M., otherwise the diagnosis will be delayed by one day. No diagnosis will be given on Sunday.

The expense of the bacteriological examination will be defrayed by the Corporation, and it is hoped that full advantage will be taken of the Copportunities thus afforded at the earliest possible period of the illness.

As the bacteriological diagnosis is more difficult during the first week f the disease, a second tube should be sent after the first week if a negative result has been obtained within the first seven days after the beginning of symptoms.

In order that medical men may familiarise themselves beforehand with the procedure which they will require to adopt a copy of Professor Delépine's instructions for taking material is enclosed.

JAMrES NIVEN, Medical Officer of Health.

\section{[Enclosure.]}

\section{Directions for Taking a SAMple of Blood for PuRposes of SERO-DIAGNOSIS.}

1. The skin of the back of the index or middle finger is first washed with soap and water and then with alcohol when possible.7

2. Meanwhile the finger can be prepared by causing congestion in one of the usual ways- $\theta$., by tying a piece of tape, not too tightly, round the root of that finger.

3. Whilst the finger is being cleaned the case containing the pipette 3. Whilst the finger is being cleaned the case containing the pipette About $?$ of an inch of the sealed point is broken off with a pair of About 18 otherwise. The point is sterilised by passing it two or three forceps or otherwise. The point is sterlised or for a few seconds just above an ordinary gas, candle, or match flame. (A deposit of soot on the glass should be avoided.)

4. The patient should be made to flex the finger as much as possible. The tightened congested skin, just above the root of the nail, should now be sharply pricked with tbe mounted sterilised needle, which is

7 In the first 500 cases, in order to obtain samples suitable for lengthy experiments, I asked that the skin should be thoroughly sterilised. This is not necessary in ordinary routine work. For the same reasons the form of pipette used has now been simplified; it consists simply of a narrow tube drawn to a point at each end, the ends being sealed. 
provided with the pipette. A pretty deep puncture can be made with sharp needle without the patient feeling it much.

5. A large drop of blood is allowed to recumulate over the puncture ; horizontal as possible.

6. With the pipette which is now cold, and without removing the aspirated from the mouthpiece, as much blood as can be obtained is aspirated gently, or allowed to run into the pipette held horizontally. large drop of blood may be obtained.

7. After driving the blood away from the broken point of the pipette by aspiration or gentle shaking, the end of the pipette is sealed by holding it in a gas, lamp, csndle, spirit, or match flame, so as to heat to redness not more than one-sixteenth of an inch. The point should be held in the flame till it is quite closed.

8. The constricted part of the pipette is then sealed in the same way after being broken across.

9. The tube containing the blood and the mounted needle are replaced in the case, which is again closed with the plaster lid.

10. All particulars are now entered on the label pasted on the case and the case is enclosed in a stamped envelope, addressed : "Bacteriological Laboratory, Owens College, Manchester."

I will now describe the so-called "typhoid outfit" (Fig. 2, page 22) as used at Manchester and will explain the apparatus and its use. The wooden case (A) in which the pipette (4) is transmitted by post has already been described in reference to Fig. 1. The guarded needle is made of an external sheath of glass (5) with a special flat needle (6) having an obtuse cutting point projecting $1 \frac{1}{2} \mathrm{~mm}$. beyond the rounded end of the glass sheath and fixed at the other extremity (7) by means of hard sealing wax; these needles can be thoroughly sterilised by heat and set by holding the needle with sterilised forceps whilst the wax is still soft. The following is a résumé of the directions given above for the collection of blood. The pipette is removed from the case and the sealed points are broken and one of them passed through a flame. The finger having been thoroughly washed with soap and water-complete sterilisation of the skin is unnecessary except for experimental purposes-the skin over the back of the last phalanx of one of the fingers is pricked sharply with the guarded needle about a quarter of an inch above the border of the skin covering the root of the nail. A drop of blood being obtained, the sterilised point of the pipette held horizontally is plunged into the drop, the blood runs freely into the pipette (B) (by lateral pressure on the finger it is easy in most cases to obtain enough blood to fill one-third, one-half, or even a greater part of the pipette). When enough blood has been collected the pipette is slightly shaken so as to free as far as possible the point from blood. This point is then sealed in a flame, the constricted part of the pipette (9) being then broken across and sealed also. When the sealed pipette containing the blood (C) reaches the laboratory it is scratched with a file or the edge of a slide at some distance from the blood (12) and the tube is then easily broken across. If desired the blood may be centrifugalised before the pipette is opened. The sterilised 
platinum $100 p^{8}$ (D) measuring $1 \mathrm{~mm}$. (internal diameter) can then be introduced through the opened end of the pipette and a drop of serum, or serum mixed with blood corpuscles, can be removed from the pipette and deposited on a sterilised cover-glass (F). It is on account of this part of the manipulation that $I$ use a pipette of a certain diameter and not any kind of capillary pipette; much time is saved and chances of contamination are aroided by this arrangement. The twenty-hours' culture of typhoid bacillus in neutral bonilion ${ }^{9}$ is poured into a glass capsule (E). Drops of the culture are taken with the sterilised loop as shown in the illustration; the loop must just touch the surface of the fluid and then be brought in contact with the cover-glass in a very slanting position as shown $(F)$. In this way it is easy to obtain perfectly equal drops ${ }^{10}$ After four, nine, or nineteen drops of culture and one drop of serum have been placed on the cover-glass they are mixed together very rapidly and thoroughly and the cover-glass is placed film downwards on a sterilised slide. If all these steps are observed absolutely accurate results will be obtained, the proportions of serum being $\frac{1}{5}, \frac{2}{1} \sigma$, or $2^{\frac{1}{2}} \sigma$. When smaller proportions are wanted the blood must first be dilated by the same method with neutral bouillon. To obtain drops of serum quite equal to those of culture it is necessary to blow the serum out of the pipette on to a glass slide. In most cases when typhoid fever has reached the end of the first week clear indications of the reaction will already be apparent at the end of one minute and after five minutes will be unmistakeable. In some cases, however, the reaction takes place slowly, so that the preparation has to be again observed at the end of half an hour and two hours. It is then possible to give a positive or negative diagnosis. We make it, however, a rule to examine again the specimen on the following day for our own information. We invariably prepare control specimens to prevent any error. I do not enter here into further details, as I have done so fully in various papers easily accessible. ${ }^{11}$

Between Oct. 10th, 1896, and the beginning of September, 1898,413 samples of blood have been tested in the laboratory. In 201 cases a positive reaction was obtained and in 198 a negative one ; in 14 the reaction was not clear and had to be reported as doubtful ; these doubtful reactions were almost always observed in cases in which the blood had been collected before the seventh day of the fever. It may therefore be said that in about 3 per cent. of the cases we failed to obtain definite results. There remain 399 cases, say 400 , in which the

8 The platinum wire I use is $0.34 \mathrm{~mm}$. thick.

9 I have on several occasions used emulsions prepared with dead bacilli, but found that living cultures were much better.

10 The drops of serum removed from the pipette in the way just described are a little smaller than those taken from the surface of the same fluid placed in a capsule or on a glass slide.

11 The Lancer, loc. cit. Brit. Med. Jour., April, 1897. 
FIG. 2.

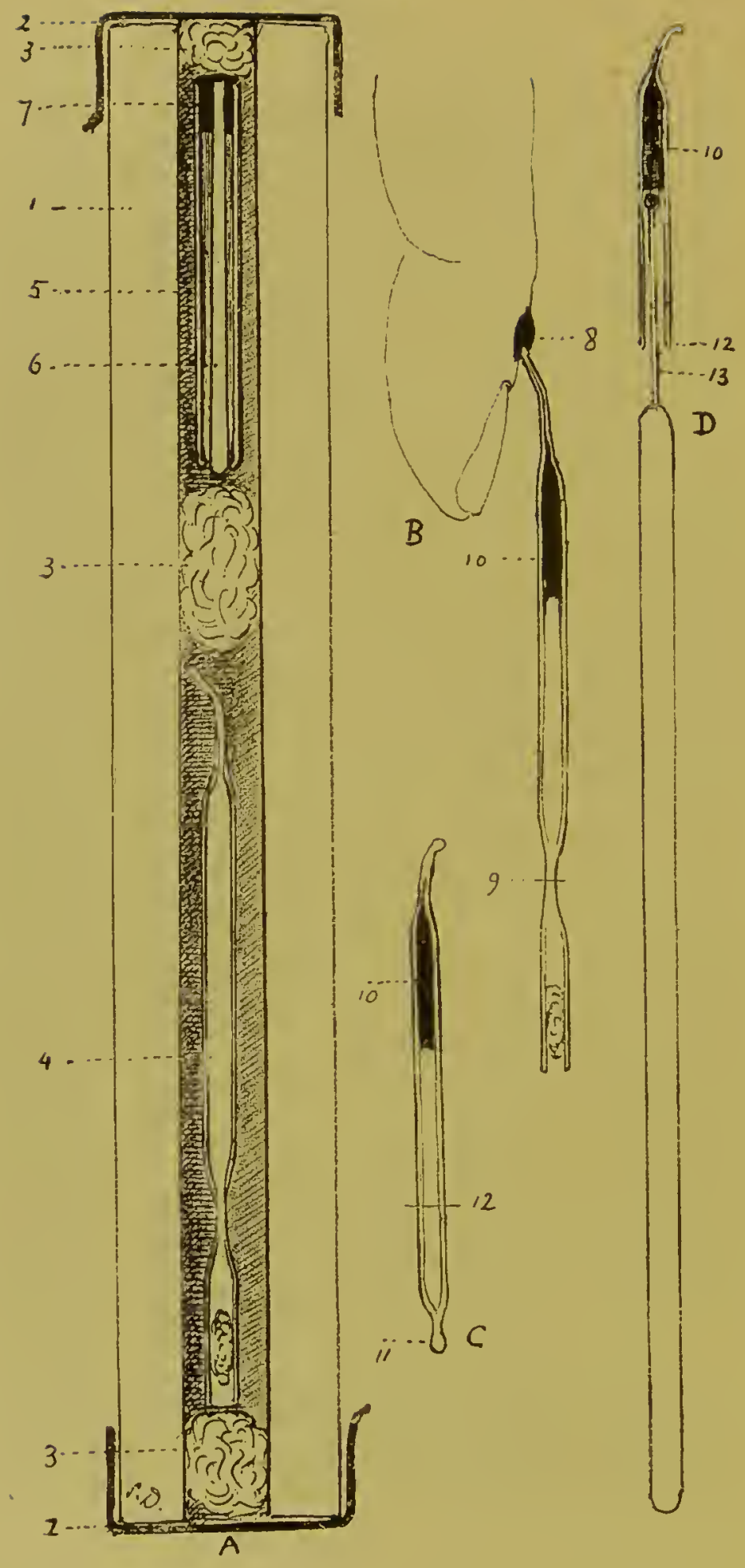



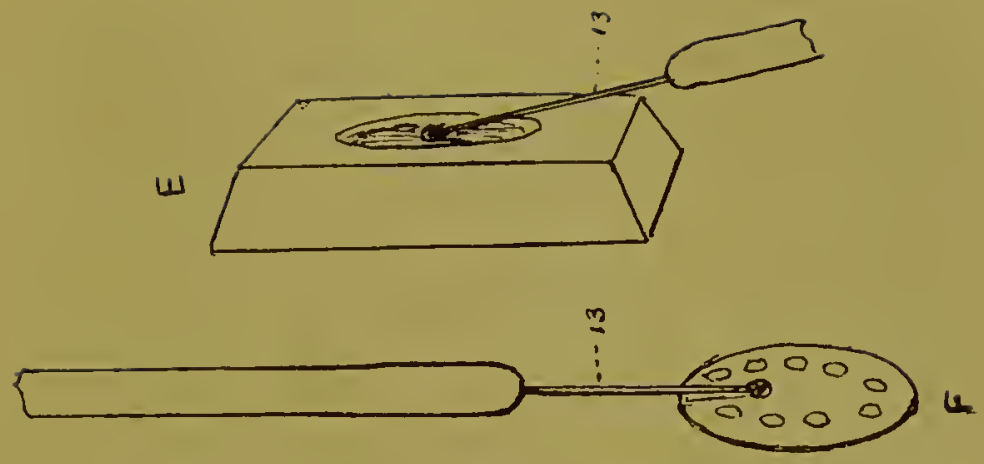

The so-called "Typhoid Outfit." A, Section of case (1); 2,2 , Antiseptic adhesive plaster ; $3,3,3$, Pads of cottonwool to prevent damsge to pipette (4) and to the glass sheath (5) of the guarded needle (6), held in position by sealing-wax (7). B shows method of collecting blood $(8$ and $10) ; 9$, Constriction of pipette. C, Pipette as received at laboratory; 11 , Where constriction $(B, 9)$ has been broken and the tube sealed; 12 , Where tube is opened for examination. D shows extraction of blood from pipette by platinum loop (13). E, Glass cepsule containing twenty-hours" culture of typhoid bacillus; 13 , Platinum loop. F, Sterilised cover-glass showing method of placing drops on cover glass by means of the platinum loop (13). The first form of pipette nsed is here represented; in the one now used both ends are alike drawn to a fine point.

reaction was evident or absent. Roughly speaking, in 50 per cent. of these the reaction was positive and in 50 per cent. negative. The negative or positive diagnosis was entirely confirmed in cases which were closely followed in hospital; some cases remained doubtfal clinically, but whenever symptoms of typhoid fever or of some other disease were unmistakeable the bacteriological diagnosis was found to be correct. We had a total of 115 cases thus controlled in Manchester. I have taken special care to control negative as well as positive results. Dince writing on this subject in THE LANCET I have examined the blood of many patients not affected with typhoid fever and have not yet found a single disease which produces in the blood properties similar to those acquired with the blood of typhoid fever patients. I have tested the blood in various septic affections, in tuberculosis, scarlet fever, measles, influenza, carcinoma, sarcoma, \&c. Owing to some remarks published by another observer I have tested the blood of several patients affected with jaundice, also placental blood and fotal blood, and in no case have I seen anything which could be mistaken for Widal's reaction when my method was used.

The cases observed in general practice gave us also very satisfactory results. I need not speak of the positive reactions which were generally accepted. But with regard to our negative results some medical men expressed doubts 


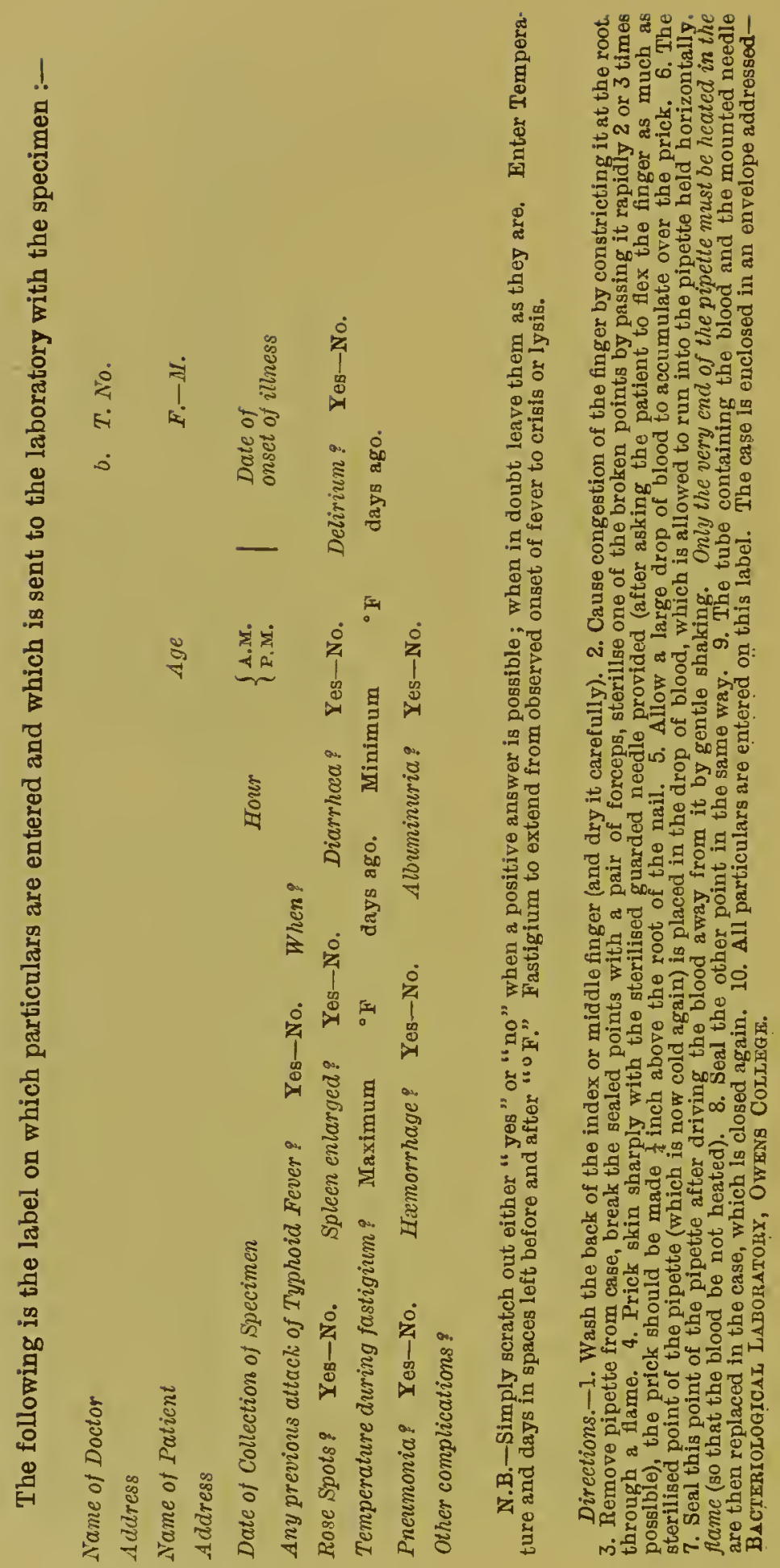


whilst others wrote afterwards expressing their satisfaction. Out of 108 letters received 88 agreed with our results and 20 disagreed; so that out of a total of 320 cases observed in Manchester and on which we gave a definite opinion in only 20 cases was the clinician in opposition to us. If I admit, as in the case of diphtheria, that the clinicians were right (which we have no special reason to admit in all these 20 cases) and that we were wrong (which is quite possible in a small proportion of cases), the error of bacteriological diagnosis would, on this basis, be 20 in 320-i.e., a little more than 6 per cent., which compares favourably with 50 per cent. doubtful cases as observed clinically. I may say that Dr. Niven has expressed himself highly satisfied with the results already obtained in Manchester.

(Since this paper was read 428 more cases have been investigated in the laboratory, this bringing the number of cases of suspected typhoid fever to 841 . The results have continued to be satisfactory; in a number of cases where the clinical symptoms seemed to be at variance with our results the further course of the case has justified the bacteriological diagnosis. Several medical men have undoubtedly refused to accept our negative reports on the ground that the symptoms were absolutely typical of typhoid fever. These, however, have been very few and there has been a marked diminution in the number of dissenters. What is more to the point, however, is that, so far, postmortem evidence has always proved the bacteriological diagnosis, whether positive or negative, to be correct with the exception of a complicated case on which I am not prepared to give a definite opinion, even after hearing the results of the post-mortem examination. I am convinced therefore that the method I have adopted as a modification of Widal's original method gives extremely reliable results.)

\section{Gengral Considerations on the Organisation oF BACTERIOLOGICAL LABORATORIES IN CONNEXION WITH Public Health Work.}

I have now given an idea of ways in which bacteriological diagnosis can be made to assist public health work and of the gain of accuracy which may be obtained. I have purposely left aside certain administrative questions which will be of special interest to those who have to consider carefully all questions of management. I think it will be evident that work of the kind I have described requires not only constant but also timely attention; delay of any kind is fatal and unless material submitted for examination be attended to punctually as soon as it reaches the laboratory diagnosis will be delayed considerably and sometimes rendered impossible. I am strongly convinced that several conditions are essential to the success of such work. 
1. The men undertaking it must be able to devote daily a part of their time to it, they must be able to do so without hurry or flurry, and in large districts they must be ready to sacrifice several of the best hours of their working-day. I doubt whether a medical officer of health, however experienced a bacteriologist he may be, can, when in charge of a large district, be master enough of his own time to attend to work of this kind when he should.

2. Though a fully equipped bacteriological laboratory is not absolutely necessary, the keeping of typical cultures in a state of activity, the testing of these cultures from time to time, the preparation of media of uniform composition, the looking after animals, \&c., are so essential to successful continuous working that, in the absence of the facilities offered by a convenient laboratory and good attendants, the task rapidly becomes a painful and tedious load. When the work is not continuous and is taken up only in time of epidemics, the expense is increased and the training resulting from daily routine is lacking, so that the investigations become extremely troublesome.

3. Even when work such as I have described is carried out in a well-fitted laboratory it is necessary that there should be in that laboratory several bacteriologists capable of undertaking the examination of morbid products and that this should be done under the direction of a man who is not likely to leave his post at the end of a few months or even years. So much depends on the care with which examinations are made that to obtain absolutely comparable results it is necessary that the same precautions be uniformly taken. To obtain uniformity in my laboratory has been one of my greatest cares. Fortunately I have been helped in this by my friend, Dr. E. J. Sidebotham, who, struck with the importance of the work, and, free to devote the whole of his time to investigation, has consented to become my assistant, or rather colleague, at the Owens College. For nearly two years, whilst my scheme was developing, and when funds were not available to obtain further assistance be shared with me all the responsible work. At first he worked jointly with me for many months till at last we found that our results were absolutely similar. Since then we have obtained the assistance of several gentlemen working in the laboratory, more especially of Dr. Brindley, who were able to relieve us of part of the work when the absence of one of us made this necessary. Yet even now all results which are not absolutely clear are checked by Dr. Sidebotham or myself or, when there is the slightest need, by both of us. In such a way absolute continuity and uniformity are secured in our work.

4. I doubt whether it would be possible for any corporation to obtain the entire services of a bacteriologist, and at the same time to get satisfactory results, without increasing very considerably the working expenses of the sanitary department. If the post were offered to a junior man with 
an inadequate salary, laboratory, and attendance, this man, if at all an able bacteriologist, would soon find a better post, and, if not capable, his results would be unreliable. But even if, by extremely careful selection, a series of young men holding office for periods of from twelve to eighteen months were obtainable, how could continuity of work be secured? The apprenticeship of each man would certainly cause variations in the results which would vitiate them all.

5. It was considerations of this kind and the desire which I had to give opportunities for a study of practical applications of bacteriology to the men working in my bacteriological laboratory at the Owens College which led me to make four years ago a scheme for associating my department with the various public health departments in Manchester and its neighbourhood. This plan received the sanction of the College council owing greatly to the interest taken in it by the Principal, Dr. A. Ward, and the Council generally. The work done in connexion with Manchester consisted at first of special investigations. It was from Dr. Porter, of Stockport, that I received three years ago the first application for systematic reporting on cases of diphtheria. Man. chester followed soon afterwards, and now more than fifteen sanitary districts are connected with the College in this way. Now from an economical and educational point of view such a combination is I think most desirable. I have found by careful calculation that with regard to reporting on diphtheria and typhoid fever it is possible when the number of cases is sufficiently large to have the work done in my laboratory and without causing any loss to the College by charging a fee of $5 s$. to the Corporation for each case reported upon. This allows me to pay all working expenses. The feeling that responsible work of public importance is going on in the laboratory is an incentive to good work and research, so that the department benefits in this way from the sacrifices which it has to make. On the other hand the towns connected with us derive advantages quite as great. Taking Manchester as an example, where through the interest taken by the Health Authority and Dr. Niven, the work is progressing in such a way as to yield already practical results, some 645 cases of diphtheria and typhoid fever have been reported upon during the twelve months ending with August, 1897, and about sixty specimens of milk have been examined. ${ }^{12}$ The cost of all these reports will be to the Corporation only a fraction of what an efficient municipal bacteriological laboratory would during the same time have cost them, and the expenditure will be more than covered by the saving effected with regard to the isolation of infectious cases. The amount received from one town

\footnotetext{
12 From returns communicated by Dr. Niven whilst this paper was in the press I hear that about 90 per cent. of all the cases notifled under the heads of diphtheria and typhold fever in Manchester, during the year 1897, have been submitted to us for bacteriological examination.
} 
only would, however, be insufficient to allow me to obtain the assistance necessary to make this work compatible with my teaching duties, and it is here that the advantage of a central laboratory becomes more evident-every town applying for reports adds in a small measure to the total of fees received, while our expenditure does not increase proportionally to the amount of work done, and in this way the laboratory as well as each town benefits from the effects of combination.

6. I think from what I have said the advantage of central laboratories will be evident. Wherever possible these laboratories should be connected with university colleges or medical schools provided with laboratories fully equipped for medical and bacteriological researches. These laboratories should not be too distant from the localities which they serve, otherwise specimens might not reach their destination in time for examination the same day and a useless delay would be produced which would interfere with the proper working of preventive measures. The delay is also objectionable on account of the changes taking place in material contaminated with bacteria. In the case of milk, for instance, if no special precautions are taken to keep it cool, bacteria multiply so rapidly in summer that it is impossible after some ten or twelve hours to get a clear idea of the original state of the fluid. In the case of anthrax difficulties may arise from the disappearance of the bacillus. Typhoid blood is more convenient in that respect because it remains quite suitable for examination after many days or even weeks. I cannot give an exact idea of the size of an area which could be worked successfully by a single laboratory; but I shall not be far wrong in saying that all towns which can be reached in less than two hours by train could easily be worked from one centre. Smaller areas would be large enough to supply constant work to a bacteriological laboratory, especially if large towns were included in them.

Before closing my remarks I wish it to be clearly understood that if I have compared clinical methods of diagnosis of certain infectious diseases with bacteriological methods to the apparent detriment of the former it is not with any desire to claim for bacteriology a superiority over clinical medicine, for: (1) without bedside study of symptoms it is impossible to determine the cases in which the assistance of bacteriology may prove useful; (2) there is a large number of diseases, even of those due to micro-organisms, in which the bacteriological methods are still too imperfect or too slow to make them applicable; and (3) the bacteriologist and the clinician should look upon each other as co-workersthe bacteriologist is able to give some assistance to the clinician within certain limits but cannot claim any personal superiority. $\mathrm{He}$ is so situated that he has the means of applying methods which cannot be easily applied in general practice but which he should place at the disposal of his 
colleagues when this can shorten and render more accurate the process of diagnosis.

How the method is to be used by authorities for the purposes of increasing the accuracy of notification is an administrative question which can be better answered by the medical officer of health than by the bacteriologist assisting him. Dr. Niven has already in several of his reports alluded to this point and I have reason to believe that before long he will make the results of his personal experience generally known.

Manchester. 
